\title{
Iliotibial band friction syndrome
}

\author{
Ronald Lavine
}

Published online: 20 July 2010

(C) Humana Press 2010

\begin{abstract}
Published articles on iliotibial band friction syndrome have been reviewed. These articles cover the epidemiology, etiology, anatomy, pathology, prevention, and treatment of the condition. This article describes (1) the various etiological models that have been proposed to explain iliotibial band friction syndrome; (2) some of the imaging methods, research studies, and clinical experiences that support or call into question these various models; (3) commonly proposed treatment methods for iliotibial band friction syndrome; and (4) the rationale behind these methods and the clinical outcome studies that support their efficacy.
\end{abstract}

Keywords Iliotibial band - Knee pain - Running injuries . Iliotibial band friction syndrome

\section{What is iliotibial band friction syndrome?}

Iliotibial band friction syndrome (ITBFS) involves pain in the region of the lateral femoral condyle or slightly inferior to it, that occurs after repetitive motion of the knee, typically in a runner, cyclist, or other athlete.

Most typically a diagnosis is made based on the case history and physical examination, though in some cases MRI's might be indicated to rule out another disorder in the region.

An important finding on physical examination is local tenderness of the lateral knee inferior to the epicondyle and superior to the joint line. The Ober test for distensibility of

R. Lavine $(\bowtie)$

Private Practice of Chiropractic, 928 Broadway, Suite 804,

New York, NY 10010, USA

e-mail: askdrlavine@gmail.com the iliotibial band is also frequently a measurement of interest.

\section{What is the prevalence of ITBFS?}

It is generally accepted that ITBFS is the most common running injury of the lateral knee, with an incidence between 1.6 and 12\%. [1-5]. Linenger states that ITBFS comprises $22 \%$ of lower extremity injuries [6].

ITBFS is also commonly diagnosed in cyclists, reported as comprising $15 \%$ of all overuse injuries of the knee region [7].

Devan and others found iliotibial band friction syndrome to be the most common overuse injury of the lower extremity in a group of female college athletes who played soccer, basketball, or field hockey [8]. Rumball et al. also noted the common occurrence of ITBFS among competitive rowers [9].

\section{What is the pathology of the condition?}

When the concept of iliotibial band friction syndrome was first developed, the presumed model was that during activities involving repetitive knee flexion (such as running), the iliotibial band repetitively shifted forward and backward over the lateral femoral condyle, causing friction and thus inflammation of the ITB.

However, this view has been called into question in several ways.

Fairclough and others reason that the ITB is not a distinct anatomical structure but merely a thickened zone within the lateral fascia, which moreover is firmly connected to the linea aspera by an intermuscular septum [10]. 
Based on these anatomical considerations, they believe that anterior-posterior glide of the ITB is impossible, and a friction syndrome cannot truly exist in the region. Instead, they propose that an illusion of anterior-posterior movement of the ITB results from repetitive cycles of tightening; with each cycle of tightening the lateral fascia exerts a repetitive compression effect on connective tissues lying deep to the ITB.

The study of Hariri and others also calls into question whether inflammation of the ITB is actually involved in ITBFS [11]. In their case series, the symptoms of ITBFS were alleviated by surgical excision of what they described as a bursa in the sub-ITB space. Costa and colleagues also reported on a case in which a large cyst, arising from the joint capsule, was discovered in a 28-year old runner with lateral knee pain [12]. Nemeth and Sanders may have been describing the same tissue in their anatomical review [13], but they referred to it as a lateral extension of the knee synovial capsule.

On the other hand, Isusi and others did not identify a bursa in the area, but did report MRI findings of signal changes from the soft tissues immediately below the ITB, and osseous edema and subchondral osseous erosion of the lateral condyle, without evidence of inflammation or thickening of the band itself [14]. Further supporting this view is the study of Muhle and others [15], whose MRI studies of both cadavers and ITBFS patients showed poorly defined signal intensity abnormalities in a compartment-like space bounded laterally by the ITB, but did not identify a bursa, cyst, or lateral recess in this area, or pathological changes in the band itself. Nemeth and Sanders reported similar findings [13].

It may be that different subtypes of iliotibial band friction syndrome exist, one that involves irritation of a cyst, bursa, or lateral synovial recess, and a second type arising from compression by the iliotibial band of the connective tissues that underlie the portion of the band between the lateral epicondyle and the knee joint line. There is less evidence that a pathological change takes place in the iliotibial band itself. Whether actual anterior-posterior friction-producing motion of the ITB takes place or not is also controversial.

\section{What are the biomechanical factors that contribute?}

Weak hip abductors?

It would be logical to correlate the presence of weak hip abductors with iliotibial band friction syndrome, since weak abductors might lead to increased hip adduction during the stance phase of gait with a consequent increase strain of the iliotibial band and a greater tendency for it to compress the tissues underneath.
MacMahon and colleagues, Noehren et al., and Fredericson et al. all reported that ITBFS sufferers had abductor weakness or increased hip adduction during the stance phase of gait, a finding which could be interpreted as being due to abductor weakness [4, 16, 17].

On the other hand, Grau et al., using a dynamometer that was mechanically stabilized instead of hand-held, did not find hip abductor weakness in their study of 10 runners with ITBFS as compared to healthy matched controls [18].

Thus, we may have more to learn about the relationship of iliotibial band friction syndrome to hip abductor weakness or to the related issues of the timing and magnitude of hip abductor activation during the gait cycle and the amount of hip adduction that occurs during the stance phase of gait.

\section{Tight iliotibial band?}

It is also logical to link tightness of the ITB with iliotibial band friction syndrome, since presumably a tighter band would lead to greater compression of the underlying tissues with each gait cycle.

The Ober test is most commonly used to assess tightness of the iliotibial band. As described by Gajdoski et al. [19], the Ober test is performed with the examiner standing behind the side-lying patient. The examiner stabilizes the pelvis with one hand, flexes the uppermost thigh, and then moves it into maximal abduction. He or she then maintains the abduction while moving the thigh into extension. The examiner then lowers the limb into adduction until it stops, or until the pelvis starts to tilt. The angle of hip joint adduction (or abduction, if the thigh cannot adduct even to neutral) is considered to be a measurement of ITB length or distensibility. Gajdoski's article also describes variations of the Ober test that call for the knee of the side being tested to be either flexed or extended.

However, no study to date has actually correlated the findings of the Ober test (or any other test for ITB distensibility) with iliotibial band friction syndrome. Moreover, Devan and others did not find a correlation between a positive Ober test and the occurrence of ITBFS in female college athletes [8].

On the other hand, Fredericson [20] believes that most athletes with ITBFS exhibit a tight iliotibial band, though the Ober test and other clinical examination methods, as they are used in common clinical practice, may not be sensitive enough to detect it.

In 2007, Hamill, Miller, Noehren, and David published findings that showed that runners with ITBFS had a "looser" iliotibial band, exhibiting increased strain (it elongated more when subject to an external load) and, to a statistically significant degree, an increased strain rate (it elongated more rapidly) during running [21]. 
These findings seem to contradict the commonly asserted link between a tight iliotibial band and ITBFS. Furthermore, they would imply that stretching the ITBinsofar as the purpose of stretching would be to increase the distensibility of the band-could accentuate the symptoms of ITBFS.

Angle of knee flexion during stance phase?

The portion of the knee range of motion at which the ITB is most likely to rub against or compress the underlying structures is with the knee flexed about $20^{\circ}-30^{\circ}$. Perhaps differences in the degree of knee flexion between individual runners play a role in the onset of ITBFS. The commonly held association of ITBFS with running downhill $[22,23]$ may be due to the fact that downhill running results in a higher degree of knee flexion at heel strike, thus increasing the friction of the ITB with the lateral epicondyle or the pressure the ITB places on the underlying softtissues.

However, Orchard et al. found no difference in the angle of knee flexion between runners with or without ITBFS when running on a treadmill [22]. This finding was echoed by Noehren et al. [17].

An additional subtlety was studied by Miller and others in 2006 [24]. Hypothesizing that a runner's biomechanics might deteriorate adversely with fatigue, they tested runners' biomechanics at the end of an exhaustive run. Indeed, runners with a history of ITBFS exhibited an increased angle of flexion of the knee at heel strike.

\section{Rearfoot eversion?}

Busseuil et al. found a higher incidence of ITBFS and other lower extremity injuries in athletes who over-pronated [25].

However, Messier et al. and Noehren's group reached the opposite conclusion, that runners with ITBFS had reduced rearfoot pronation as compared to controls $[3,17]$.

\section{Other biomechanical factors}

Other biomechanical factors that have been linked with iliotibial band friction syndrome include: increased landing forces, increased knee internal rotation, low hamstring strength as compared to the quadriceps strength on the same side, and genu recurvatum [3, 8, 17, 25].

\section{What other injuries and conditions are related to ITBFS?}

Tightness of the ITB may play a role in patellofemoral syndrome [26-28].
Vasilevska's group studied patients with osteoarthritis of the medial compartment of the knee and found a high incidence of iliotibial band friction syndrome. Their model was that reduced medial joint space created a varus knee deformation, thus putting extra tension into the iliotibial band [29].

Greater trochanteric pain syndrome (previously known as trochanteric bursitis) may also reflect altered biomechanics of the ITB.

Pelfert and others have reported the occurrence of ITBFS subsequent to repair of the anterior cruciate ligament [30].

Costa and others reported having removed a synovial cyst from the lateral knee of a runner diagnosed with iliotibial band friction syndrome [12].

Hammer reports the common occurrence of various hip and knee problems in those with iliotibial band friction syndrome, though the individual manifestations vary so that no consistent associations can be made between ITBFS and any other specific syndrome [31].

\section{How is iliotibial band friction syndrome treated?}

As described by Fredericson and others, the accepted treatment of iliotibial band friction syndrome follows the outline common to the treatment for many connective tissue injuries, beginning with treatment of the acute inflammatory response and progressing through a corrective treatment phase and ultimately to a return to regular activity [32].

Acute phase treatment to limit the inflammatory response

Care in the acute phase focuses on activity limitation or modification, and measures to relieve pain and inflammation, such as ice, oral NSAID's, or corticosteroids delivered via phonophoresis or injection.

There is a limited body of research establishing the effectiveness of any of these measures in ITBFS. Ellis et al., in a review of published trials of therapy for ITBFS, found only one prior study of adequate quality that tested the use of NSAIDs, and two other studies that focused on the use of corticosteroids, in one case applied via phonophoresis and in the other via injection. In all three studies, improvement was demonstrated in both the control group and the treatment group, but the groups receiving antiinflammatory agents showed significant improvement compared to those that did not [33].

On the other hand, other research, not specific to ITBFS, points to the risks of these anti-inflammatory measures when treating connective tissue injuries, and raises the 
possibility that the pharmaceutical limitation of the inflammatory stage in connective tissue injury actually leads to a delay in healing or to poorer healing [34, 35].

Stretching of the iliotibial band and related structures

Stretching of the iliotibial band, lateral fascia, gluteus medius, and other muscles is frequently recommended as part of the treatment plan for ITBFS.

A variety of stretching protocols have been suggested. Fredericson measured the change in length of the iliotibial band while athletes performed variations of ITB stretches, and found that a particular stretch-with the athlete standing, placing the affected foot adducted and behind the other, and laterally flexing away from the affected side with the arms stretched overhead-created the greatest lengthening of the band [36].

On the other hand, Falvey et al. found that the optimal stretch varied considerably from individual to individual [37].

Neither study documents a link between short term distension of the iliotibial band, such as during a stretching routine, and longer-term changes in the tissue's mechanical response, in improved running mechanics, or in relief of ITBFS. In addition, in light of the discussion above on the questionable role of iliotibial band tightness on the etiology of the disease, there may be reason to question the rationale for attempting to stretch the ITB.

\section{Connective tissue manipulation}

Manual therapy techniques to release myofascial restrictions in the iliotibial band and related structures are also frequently recommended.

Pedowitz reported on a single case that he treated effectively with strain-counterstrain technique [38]. Hammer emphasizes the use of connective tissue treatment methods to release restrictions not only in the ITB but in the gluteal muscles and any other areas found to be restricted in the hip area, thigh, or lower extremity [31]. Fredericson agrees that treatment of trigger points in the band can help significantly [20].

On the other hand, of the scarce published data that has tested the efficacy of these measures, Ellis et al. found a single trial of deep transverse friction massage used in the treatment of ITBFS. It was not found to confer any added benefit [33].

Strengthening of the hip abductors

Though no trials have been published on the efficacy of strengthening exercises in the treatment of ITBFS, strengthening of hip abductors is often recommended [32].
Improved neuromuscular coordination

Improving neuromuscular control of gait is also frequently mentioned as a useful approach in the treatment of ITBFS. Fredericson et al. depicted a number of exercises to train complex multidimensional movement patterns involving weight shift and other aspects of hip abductor function [32]. Pettit and Dolski also described the successful application of a multi-dimensional corrective therapeutic exercise program combined with stretching, massage, soft tissue mobilization, shoe modification, and electrical stimulation [39].

Surgical excision of a cyst, bursa, or lateral synovial recess

Practitioners utilizing conservative means report a satisfactorily high rate of positive response, so that few patients should require surgical intervention [2, 40-42]. Yet a number of case series reporting resolution of ITBFS from the surgical excision of a bursa, cyst, or portion of a lateral synovial recess have been published [11-13, 43].

\section{Summary}

Iliotibial band friction syndrome is a common occurrence among physically active individuals, causing pain in the lateral knee.

There is much to be learned about the etiology, pathology, and optimal treatment of the condition. Many published studies seem to approach the problem from differing and hard-to-reconcile viewpoints.

Despite these limitations, and despite the fact that few outcome studies have been done to establish a consensus clinical approach, most practitioners are confident in their ability to diagnose ITBFS based on the case history and physical examination, and most are satisfied with the treatment results they get with conservative measures that include methods to control the inflammatory reaction, strengthening, stretching, modification of neuromuscular control of gait, and connective tissue therapy. Corticosteroids and NSAID's have documented benefits in the short term.

In those few cases that do not respond to a conservative regimen, surgical excision of tissues deep to the band also has an established track record of effectiveness.

\section{References}

1. Orava S. Iliotibial tract friction syndrome in athletes-an uncommon exertion syndrome on the lateral side of the knee. Br J Sports Med. 1978;12:69-73.

2. McNicol K, Taunton J, Clement D. Iliotibial tract friction syndrome in athletes. Can J Appl Sport Sci. 1981;6(2):76-80. 
3. Messier SP, Edwards DG, Martin DF, Lowery RB, Cannon DW, James MK, et al. Etiology of iliotibial band friction syndrome in distance runners. Med Sci Sports Exerc. 1995;27:951-60.

4. Fredericson M, Cookingham CL, Chaudhari AM, et al. Hip abductor weakness in distance runners with iliotibial band syndrome. Clin J Sport Med. 2000;10:169-75.

5. Taunton J, Ryan M, Clement D, McKenzie D, Lloyd-Smith D, Zumbo B. A retrospective case-control analysis of 2002 running injuries. Br J Sports Med. 2002;36(2):95-101.

6. Linenger JMCC. Is iliotibial band syndrome overlooked? Phys Sports Med. 1992;20:98-108.

7. Holmes JC, Pruitt AL, Whalen NJ. Iliotibial band syndrome in cyclists. Am J Sports Med. 1993;21(3):419-24.

8. Devan MR, Pescatello LS, Faghri P, Anderson J. A prospective study of overuse knee injuries among female athletes with muscle imbalances and structural abnormalities. J Athl Train. 2004; 39(3):263-7.

9. Rumball JS, Lebrun CM, DiCiacca SR, Orlando K. Rowing injuries. Sports Med. 2005;35(6):537-55.

10. Fairclough J, Hayashi K, Toumi H, Lyons K, Bydder G, Phillips $\mathrm{N}$, Best $\mathrm{T}$, Benjamin $\mathrm{M}$. Is iliotibial band syndrome really a friction syndrome? J Sci Med Sport. 2007;10:74-6.

11. Hariri S, Savidge ET, Reinold MM, Zachazewski J, Gill TJ. Treatment of recalcitrant iliotibial band friction syndrome with open iliotibial band bursectomy: indications, technique, and clinical outcomes. Am J Sports Med. 2009;37(7):1417-24.

12. Costa ML, Marshall T, Donell ST, Phillips H. Knee synovial cyst presenting as iliotibial band friction syndrome. Knee. 2004;3: 247-8.

13. Nemeth WC, Sanders BL. The lateral synovial recess of the knee: anatomy and role in chronic Iliotibial band friction syndrome. Arthroscopy. 1996;12:574-80.

14. Isusi M, Oleaga L, Campo M, Grande D. MRI findings in iliotibial band friction syndrome: a report of two cases. Radiologia. 2007;6:433-5.

15. Muhle C, Ahn J, Yeh L, Bergman G, Boutin R, Schweitzer M, Jacobson J, Haghighi P, Trudell D, Resnick D. Iliotibial band friction syndrome: MR imaging findings in 16 patients and MR arthrographic study of six cadaveric knees. Radiololgy. 1999; 212(1):103-10.

16. MacMahon JM, Chaudhari AM, Andriacchi TP. Biomechanical injury predictors for marathon runners: striding towards iliotibial band syndrome injury prevention. Conference of the International Society of Biomechanics in Sports, Hong Kong; June 2000.

17. Noehren B, Davis I, Hamill J. Prospective study of the biomechanical factors associated with iliotibial band syndrome. Clin Biomech. 2007;22:951-6.

18. Grau S, Krauss I, Malwald C, Best R, Horstmann T. Hip abductor weakness is not the cause for iliotibial band syndrome. Int $\mathbf{J}$ Sports Med. 2008;29(7):579-83.

19. Gajdosik R, Sandler M, Marr H. Influence of knee positions and gender on the Ober test for length of the iliotibial band. Clin Biomech. 2003;18:77-9.

20. Fredericson M, personal communication, 2009.

21. Hamill J, Miller R, Noehren B, Davis I. A prospective study of iliotibial band strain in runners. Clin Biomech. 2008;23:1018-25.

22. Orchard J, Fricker P, Abud A, Mason B. Biomechanics of iliotibial band friction syndrome in runners. Am J Sports Med. 1996;24:375-9.
23. Noble C. Iliotibial band friction syndrome in runners. Am $\mathbf{J}$ Sports Med. 1980;8:232-4.

24. Miller R, Lowry J, Meardon S, Gillette J. Lower extremity mechanics of iliotibial band syndrome during an exhaustive run. Gait Posture. 2007;26:407-13.

25. Busseuil C, Freychat P, Guedj EB, Lacour JR. Rearfoot-forefoot orientation and traumatic risk for runners. Foot Ankle Int. 1998;19:32-7.

26. Wilson NA, Press JM, Koh JL, Hendrix RW, Zhang LQ. In vivo noninvasive evaluation of abnormal patellar tracking during squatting in patients with patellofemoral pain. J Bone Joint Surg Am. 2010;3:558-66.

27. Merican AM, Amis AA. Iliotibial band tension affects patellofemoral and tibiofemoral kinematics. J Biomech. 2009;10: 1539-46.

28. Hudson Z, Darthuy E. Iliotibial band tightness and patellofemoral pain syndrome: a case-control study. Man Ther. 2008;2:147-51.

29. Vasilevska V, Szeimies U, Stäbler A. Magnetic resonance imaging signs of iliotibial band friction in patients with isolated medial compartment osteoarthritis of the knee. Skeletal Radiol. 2009;9:871-5.

30. Pelfort X, Monllau JC, Puig L, Cáceres E. Iliotibial band friction syndrome after anterior cruciate ligament reconstruction using the transfix device: report of two cases and review of the literature. Knee Surg Sports Traumatol Arthrosc. 2005;6:586-9.

31. Hammer W, personal communication, 2009.

32. Fredericson $M$, Wolf $C$. Iliotibial band syndrome in runners: innovations in treatment. Sports Med. 2005;35:451-9.

33. Ellis R, Hing W, Reid D. Iliotibial band friction syndrome-a systematic review. Man Therapy. 2007;12:200-8.

34. Almekinders L. An in vitro investigation into the effects of repetitive motion and non-steroidal anti-inflammatory medication on human tendon fibroblasts. Am J Sports Med. 1995;23: 119-23.

35. Kulick M. Oral ibuprofen: evaluation of its effect on peritendinous adhesions and the breaking strength of a tenorrhaphy. J Hand Surg. 1986;11A:110-9.

36. Fredericson M, White J, MacMahon J, Andriacchi T. Quantitative analysis of the relative effectiveness of 3 iliotibial band stretches. Arch Phys Med Rehabil. 2002;83(5):589-92.

37. Falvey, EC, Clark RA, Franklyn-Miller A, Bryant AL, Briggs C. Iliotibial band syndrome: an examination of the evidence behind a number of treatment options. Scand J Med Sci Sports. 2009 Aug 27. doi:10.1111/j.1600-0838.2009.00968.x.

38. Pedowitz RN. Use of osteopathic manipulative treatment for iliotibial band friction syndrome. J Am Osteopath Assoc. 2006;12: $563-7$.

39. Pettitt R, Dolski A. Corrective neuromuscular approach to the treatment of iliotibial band friction syndrome: a case report. J Athl Train. 2000;35:96-9.

40. Anderson G. Iliotibial band friction syndrome. Aust J Sci Med Sport. 1991;23(3):81-3.

41. Kirk K, Kuklo T, Klemme W. Iliotibial band friction syndrome. Orthopedics. 2000;23(11):1209-15.

42. Levin J. Run down: battling IT band syndrome in long distance runners. Biomechanics. 2003;1:22-5.

43. Drogset JO, Rossvoll I, Grontvedt T. Surgical treatment of iliotibial band friction syndrome. A retrospective study of 45 patients. Scand J Med Sci Sports. 1999;9:296-8. 